\title{
Travel Time Modelling Using Time Series of Nitrate Concentration in Groundwater Improves Hydrological Process Understanding : A Case Study of a Small Agricultural Catchment in Brittany, France.
}

\author{
Baibaswata Bhaduri ${ }^{1}$, Muddu Sekhar ${ }^{1}$, Ophélie Fovet ${ }^{2}$, and Laurent Ruiz ${ }^{3}$ \\ ${ }^{1}$ Indian Institute of Science \\ ${ }^{2}$ INRA Site d'Agrocampus Ouest \\ ${ }^{3}$ Institut de Recherche pour le Développement Délégation Régionale Occitanie
}

September 25, 2021

\begin{abstract}
Rivers can act as mirrors to in-catchment processes, but integrated concentration-discharge dynamics might not be sufficient for constructing a well-posed solute travel time determination problem. One remedy is to look inside the catchment and see if the extra information provided by long-term time series of groundwater solutes constrains the problem or provides us with some additional insight on retrieving the processes which the stream is aggregating. To test this notion, we used data for Kerrien, a well-studied agriculture dominated small headwater catchment of the French Critical Zone Observatory in Brittany. It contains long-term nitrate concentration time-series from a network of piezometers as well as a stream outlet. In this study, a parsimonious, conceptual dual-permeability mixing model already developed for streams was adapted for piezometers along with detailed uncertainty and sensitivity analysis. We found out the nitrate flushing times of mid to upslope piezometers were consistently higher than the stream outlet. We further observed an asynchronicity in seasonal concentration-discharge dynamics between the piezometers and the stream. We hypothesize the reason behind this counterintuitive finding to be extensive riparian denitrification, vertical stratification of groundwater and disconnect between the stream and the deeper flowpaths that carry legacy contamination, evidenced by the non-closure of water budget at the stream outlet. As a consequence, we argue that in headwater catchments the stream signature might not fully reflect internal processes which can be revealed only by using piezometer data. This adapted conceptual framework could be of great interest for semi-arid catchments where groundwater monitoring could be used in combination or as an alternate to ephemeral streams in travel time determination.
\end{abstract}

\section{Hosted file}

Manuscript.docx available at https://authorea.com/users/437419/articles/539067-traveltime-modelling-using-time-series-of-nitrate-concentration-in-groundwater-improveshydrological-process-understanding-a-case-study-of-a-small-agricultural-catchment-inbrittany-france 

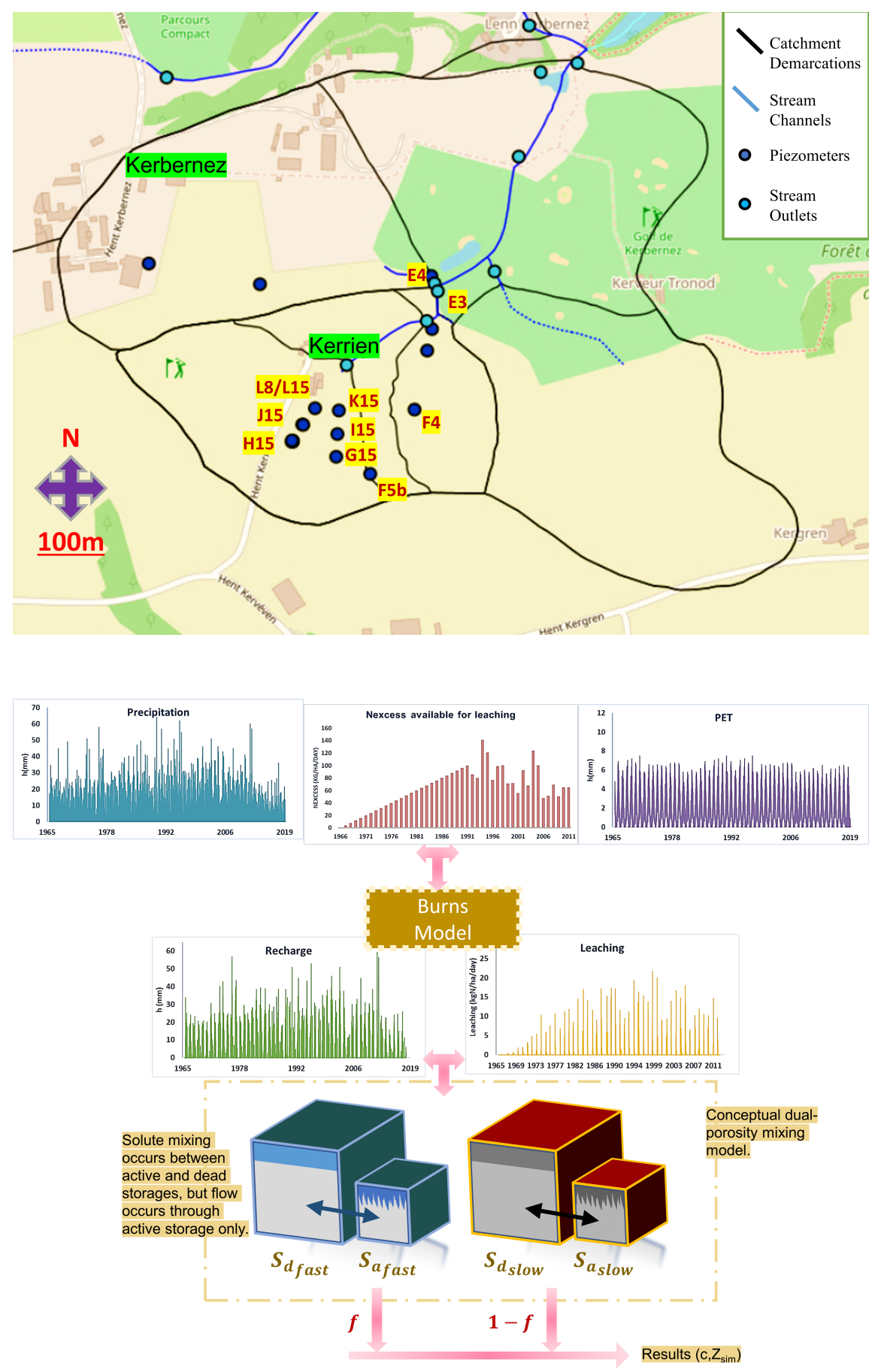

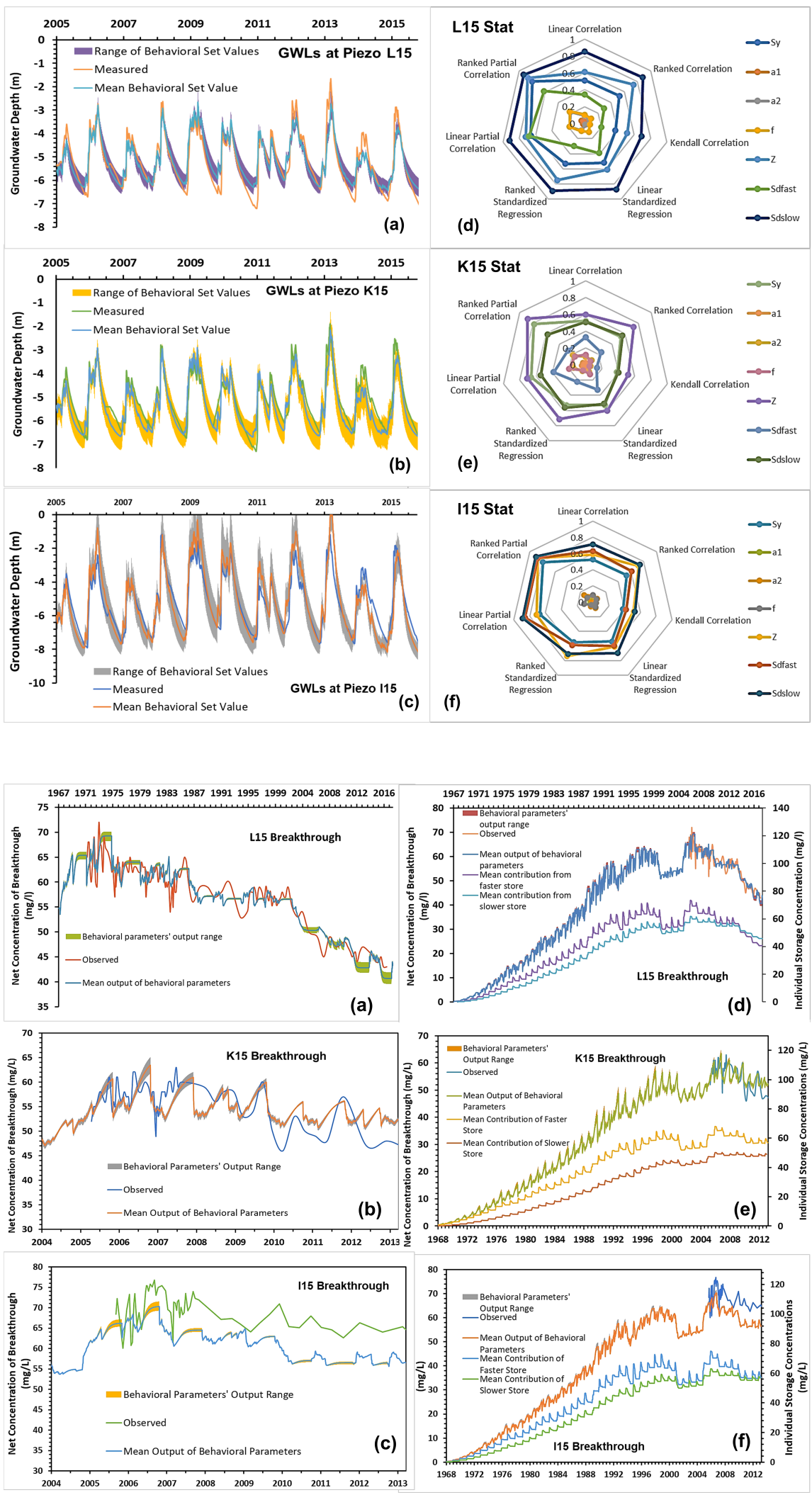

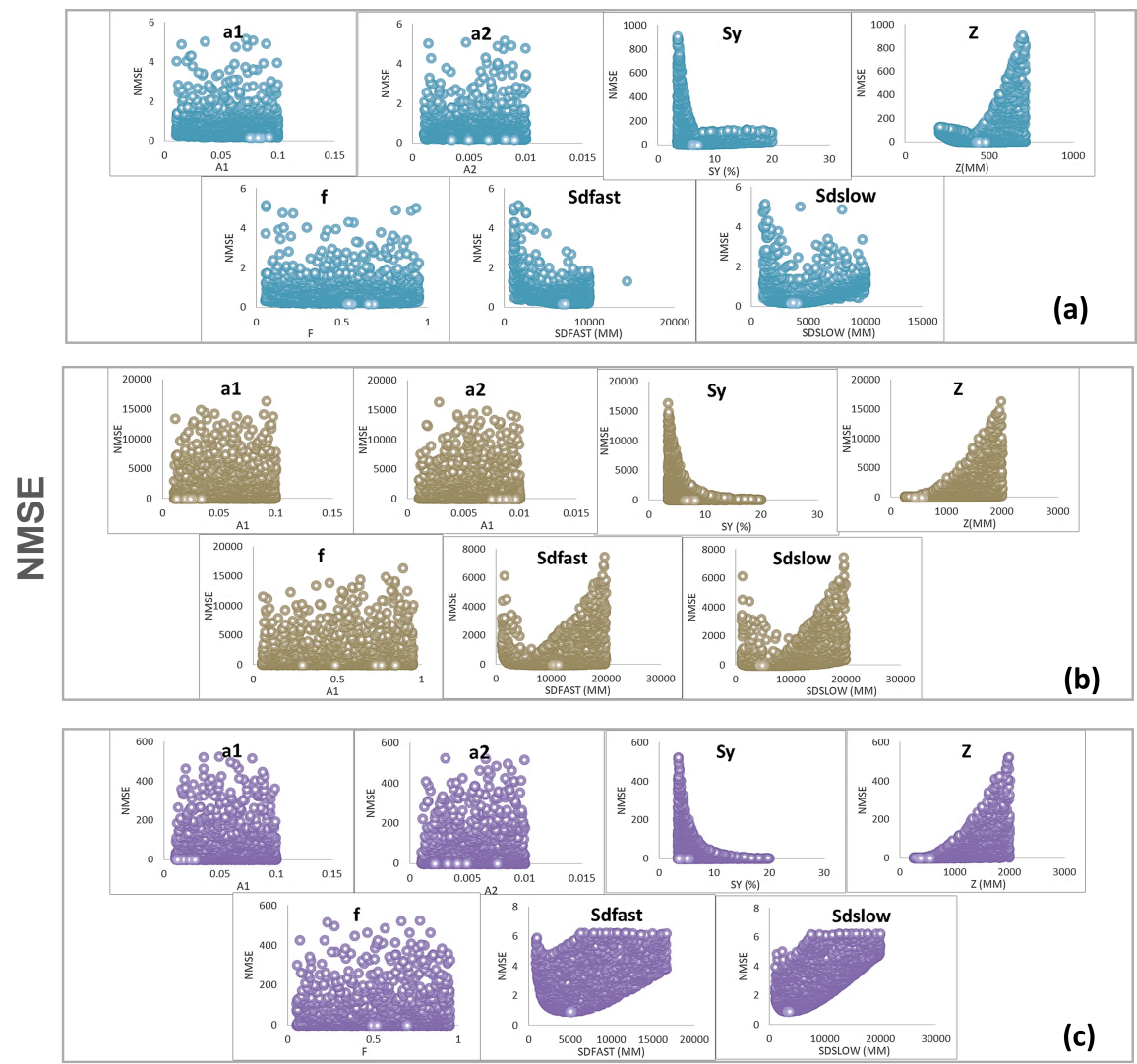

\section{Parameter Values}

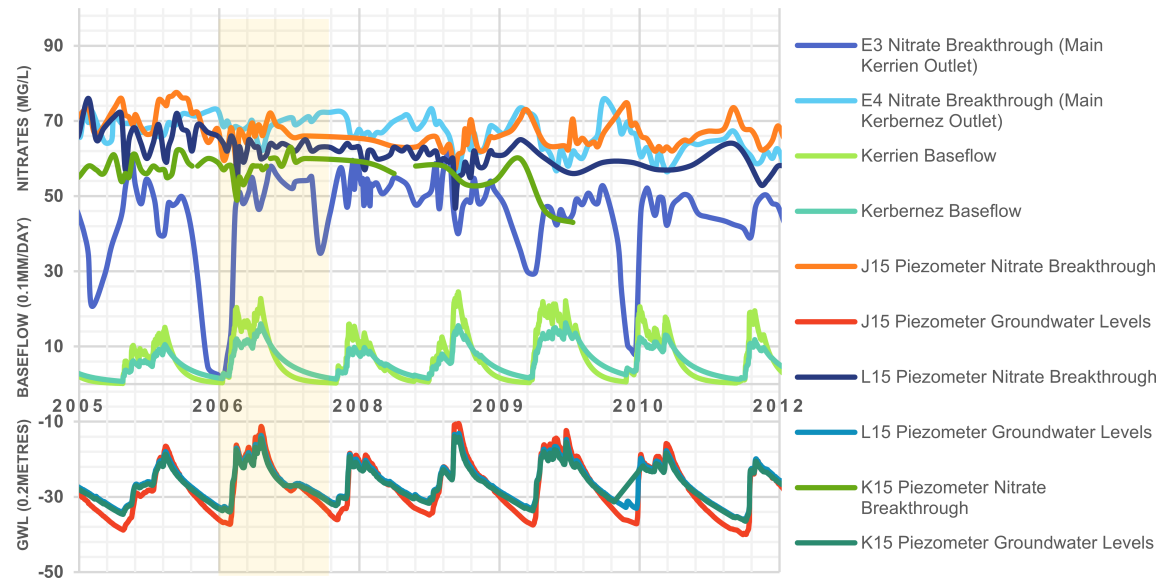


input (recharge and

leached nitrogen

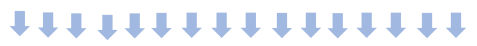
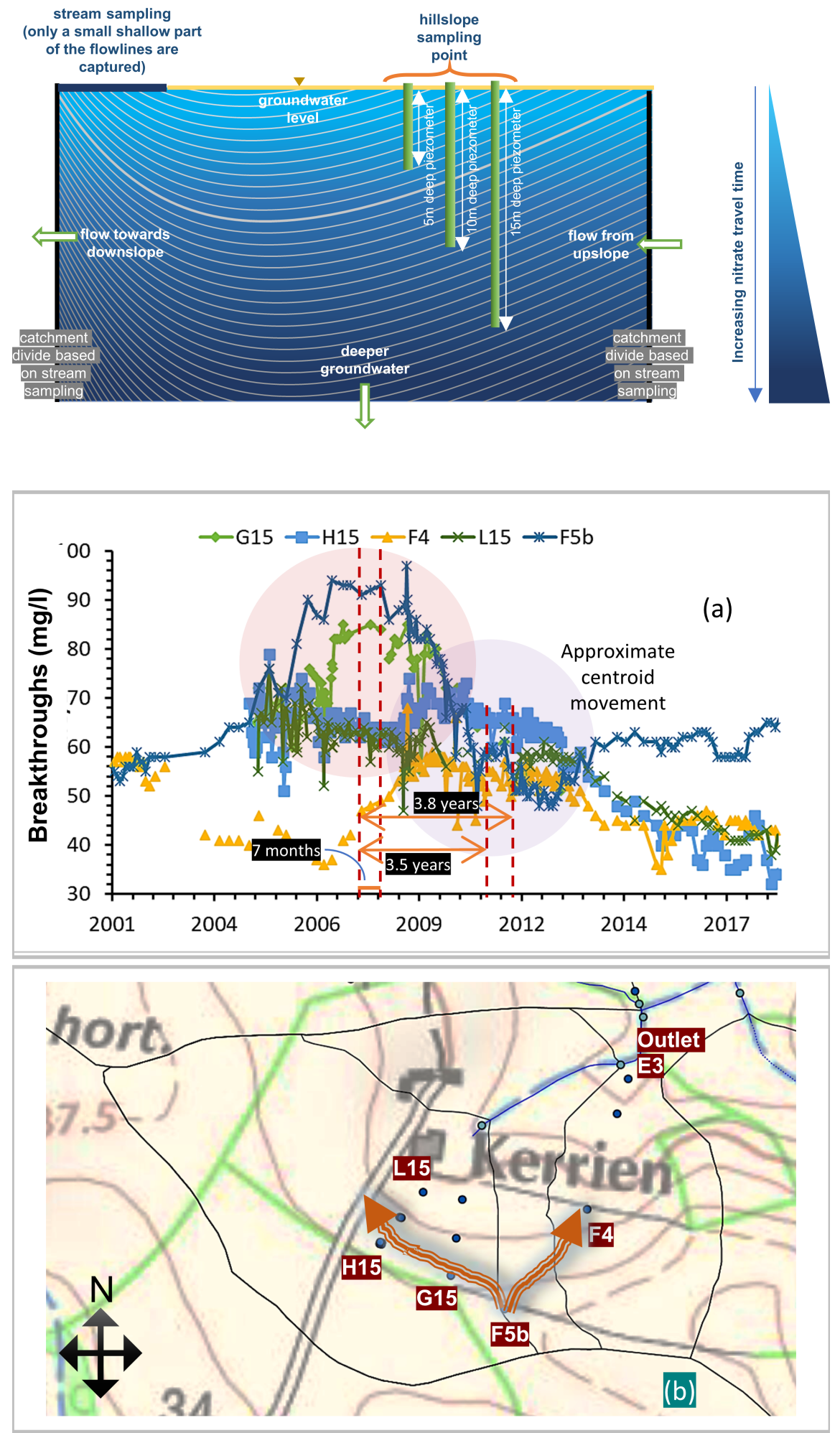


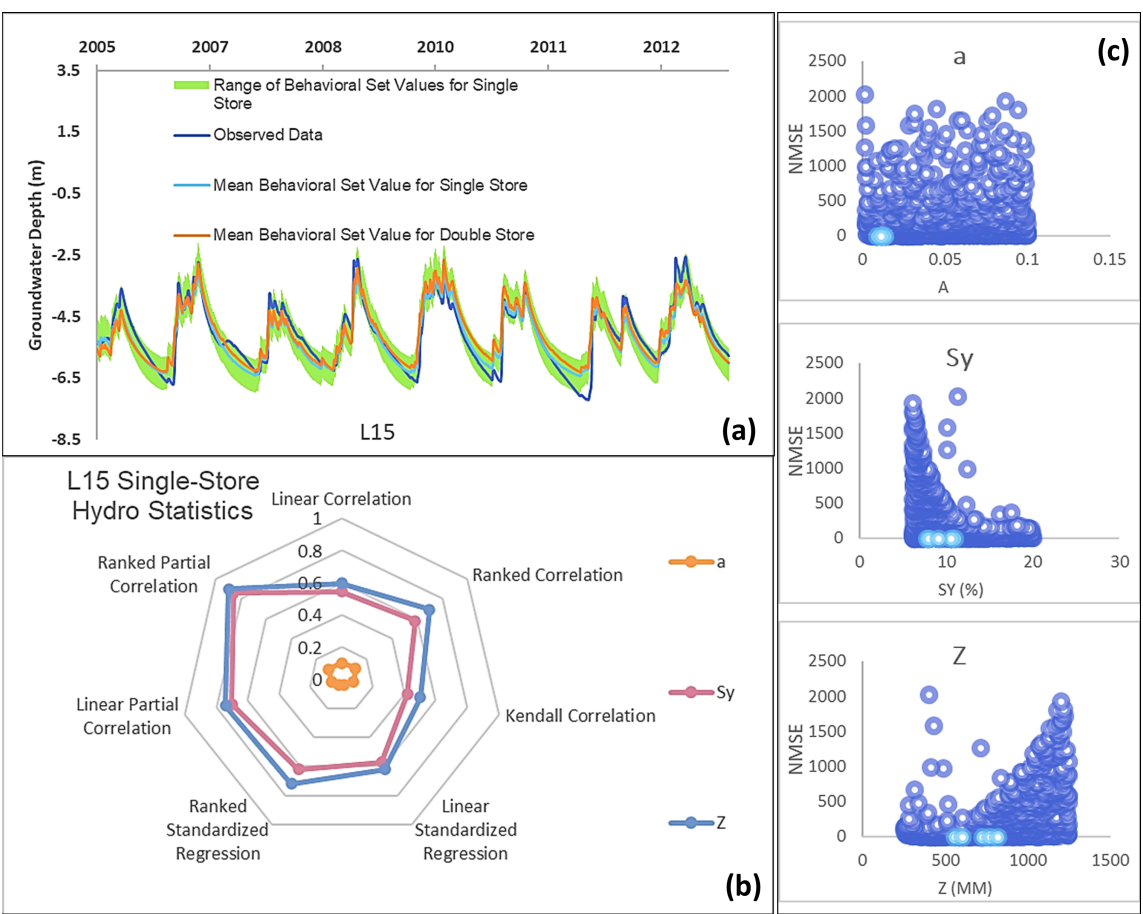

